\title{
A política externa dos EUA, os golpes no Brasil, no Chile e na Argentina e os direitos humanos
}

Mariana Joffily ${ }^{1 *}$

\section{RESUMO}

Com base em documentos de agências governamentais, este artigo analisa a política dos EUA em relação aos golpes militares perpetrados no Brasil (1964), no Chile (1973) e na Argentina (1976) em um período em que o tema dos direitos humanos emergia na esfera pública, desafiando a lógica de contrainsurgência da Guerra Fria. Argumenta-se que o dilema criado pelo dano à imagem dos EUA devido à associaçáo com regimes autoritários foi encarado com base na avaliaçáo, caso a caso, sobre os riscos que um recuo traria para seus interesses econômicos, políticos e de segurança. Em um processo histórico que levaria posteriormente à eleição de Jimmy Carter, a linguagem dos direitos humanos foi sendo progressivamente incorporada na política externa estadunidense, primeiro a contragosto, em seguida de forma estratégica, em momentos quando se avaliou que nem os negócios nem a segurança estadunidense estavam ameaçados.

Palavras-chave: ditaduras do Cone Sul; política externa estadunidense; direitos humanos; Guerra Fria.

\section{US Foreign Policy, the Coups in Brazil, Chile and Argentina, and Human Rights}

\section{ABSTRACT}

Based on documents from governmental agencies, this paper analyses US policy regarding the military coups in Brazil (1964), Chile (1973) and Argentina (1976) in a period when concerns about human rights were rising in the US public sphere, challenging the Cold War logic of counterinsurgency. We argue that the dilemma created by the damage to the image of the US due to its association with authoritarian regimes was addressed in terms of a case-by-case evaluation of the risks a retreat would pose to the economic, political and security interests of the US. In a historical process that would later lead to Jimmy Carter's election,

DOI: http://dx.doi.org/10.1590/2237-101X01903803

Artigo recebido em 25 de julho de 2017 e aprovado para a publicação em 19 de novembro de 2017.

${ }^{1}$ Universidade do Estado de Santa Catarina, Florianópolis, Santa Catarina, Brasil.

*Professora da Universidade do Estado de Santa Catarina. E-mail: mariana.joffily@gmail.com. 
the language of human rights was progressively incorporated into US foreign policy, first unwillingly and then strategically, at moments when neither the businesses nor the security of the US were threatened.

Keywords: Southern Cone dictatorships; US foreign policy; human rights; Cold War

\section{La política externa de los EEUU, los golpes en Brasil, Chile y Argentina, y los derechos humanos}

\section{RESUMEN}

Con base en documentos de agencias gubernamentales, este artículo analiza la política de los EEUU en relación a los golpes militares de Brasil (1964), Chile (1973) y Argentina (1976), en un período en el cual el tema de los derechos humanos emergía en la esfera pública, desafiando la lógica de contrainsurgencia de la Guerra Fría. Se argumenta que el dilema creado por el daño a la imagen de los EEUU debido a su asociación con regímenes autoritarios fue encarado con base en la evaluación, caso a caso, de los riesgos que un retroceso traería para sus intereses económicos, políticos y de seguridad. En un proceso histórico que llevaría posteriormente a la elección de Jimmy Carter, el lenguaje de los derechos humanos fue progresivamente incorporado por la política externa estadunidense, primero contra su voluntad, en enseguida de manera estratégica, en momentos en los cuales se evaluó que ni los negocios, ni la seguridad de los EEUU estaban amenazados.

Palabras clave: dictaduras del Cono Sur; política externa estadunidense; derechos humanos; Guerra Fría.

No exterior, os generais latinos são vistos como nossos parceiros ${ }^{2}$

Domingo, 11 h50 de uma manhã de setembro de 1973. O presidente dos EUA, Richard Nixon, inteirava-se das novidades em uma conversa telefônica com seu assessor de segurança nacional. Os interlocutores trocavam congratulaçóes por seu papel na derrubada do presidente eleito do Chile, ocorrida cinco dias antes. Duas passagens da fala de Henry Kissinger, nessa conversa aparentemente banal, dão pistas da intrusão de um novo elemento nos cálculos da política externa estadunidenses dos anos 1970. A primeira, uma referência às críticas da imprensa: "A questão

\footnotetext{
2 "Internationally, the Latin generals look like our guys." ARA monthly report. The third world war and South America. 3/8/1976. NSA, AR00356. CL01472, p. 11. (Todas as traduçôes do inglês e do espanhol, cujos originais são citados em nota de rodapé, são de minha autoria.)
} 
chilena está se consolidando e, claro, os jornais estão sangrando porque um governo pró-comunista foi derrubado." $\mathrm{A}$ segunda, indica a mudança dos tempos: "(...) na época de Eisenhower, seríamos heróis." ${ }^{\text {” }}$ No referido período, a CIA promoveu uma operação secreta levando à derrubada de Jacobo Arbenz na Guatemala em 1954. Alguns meses antes do golpe, o embaixador John Peurifoy evocava na Time Magazine a opinião pública estadunidense não para criticar, mas para justificar a ação contra o presidente eleito: "A opinião pública nos EUA pode nos forçar a adotar algumas medidas para evitar que a Guatemala caia no colo do comunismo. Náo podemos permitir que uma república soviética se estabeleça entre o Texas e o canal do Panamá."5

Passadas quase duas décadas, a configuração da política interna dos EUA alterara-se sensivelmente. O movimento pelos direitos humanos afirmou-se, em parte em razão das sucessivas crises enfrentadas pelo país durante a guerra do Vietnã, das lutas pelos direitos civis e do escândalo do Watergate, em outra pela atuação dos próprios exilados das ditaduras do Cone Sul. Esta última, com a mobilização de organizaçóes da sociedade civil, de setores religiosos, de grupos de exilados políticos e mesmo de setores conservadores, atraiu a simpatia e inspirou iniciativas de uma parcela do Congresso estadunidense. E, em seguida, forçaria sua entrada no resistente Departamento de Estado.

O tema da irrupção dos direitos humanos nos EUA nos anos 1970 tem recebido atenção da academia, sobretudo por sua enorme expansão no período. ${ }^{6}$ Kenneth Cmiel situa o fenômeno como parte integrante da globalização, paralelo ao fluxo transnacional do capital. ${ }^{7} \mathrm{O}$ movimento desde cedo centrou-se nos direitos do indivíduo diante da violência patrocinada pelo Estado por razóes políticas. Nesse sentido, os movimentos de resistência às ditaduras do Cone Sul tiveram papel importante para sua deflagração e seu desenvol-

\footnotetext{
3 "The Chilean thing is getting consolidated and of course the newspapers are bleeding because a proCommunist government has been overthrown." Memorando de conversa telefônica entre o presidente Richard Nixon e o assessor de segurança nacional dos EUA. 16/9/1973. NSA, CL00814. Citado em parte no livro de KORNBLUH, Peter. The Pinochet File. Nova York: New Press, 2013.

4 "(...) in the Eisenhower period we would be heroes." Idem.

5 "Public opinion in the U.S. might force us to take some measures to prevent Guatemala from falling into the lap of international Communism. We cannot permit a Soviet republic to be established between Texas and the Panama Canal.” Time Magazine, v. 63, n. 2, p. 29, 11 jan. 1954. James Green lembra que embora poucos liberais ou sindicalistas estadunidenses estivessem preocupados com a América Latina, “(...) revistas liberais e progressistas se juntaram à enfraquecida 'velha esquerda' na denúncia ao golpe político levado a cabo pela CIA na Guatemala em 1954.” GREEN, James. Apesar de você. São Paulo: Companhia das Letras, 2009, p 100.

${ }^{6}$ ECKEL, Jan; MOYN, Samuel (Eds.). The Breakthrough. Human Rights in the 1970's. Pensilvânia: University of Pennsylvania Press, 2014; KEYS, Barbara J.; KECK, Margaret E. Activist Beyond Borders: Advocacy Networks in International Politics. Ithaca, NY: Cornell University Press, 1998; SCHMIDLI, William Michael. The Fate of Freedom Elsewhere. Ithaca, NY: Cornell University Press, 2013; SCHMITZ, David F. The United States and Right-wing Dictatorships. Cambridge: Cambridge University Press, 2006. MORGAN, Michael Cotey. The Seventies and the Rebirth of Human Rights, In: FERGUSON, Niall; MAIER, Charles S.; MANELA, Erez; SARGENT, Daniel J. The Shock of the Global: the 1970s and the Rebirth of Human Rights. Cambridge, MA: Belknap Press of Harvard University Press, 2010, p. 237-250. ${ }^{7}$ CMIEL, Kenneth. The Emergence of Human Rights Politics in the United States. Journal of American History, v. 86, n. 3, p. 1232, 1999.
} 
vimento, inclusive pela capacidade que tinham os perseguidos latino-americanos, por seu perfil intelectualizado e suas conexóes internacionais, de despertar solidariedade nos setores progressistas da elite estadunidense.

As relações dos EUA com ditaduras militares, em especial as do Cone Sul, foram igualmente objeto de uma bibliografia recente, que ora se debruça sobre relaçóes bilaterais, ${ }^{8}$ ora sobre as ambiguidades da política externa estadunidense, ${ }^{9}$ a manipulação da pauta de direitos humanos ${ }^{10}$ e os padrôes de conduta na relação com diversos regimes autoritários. ${ }^{11}$ Interessa-nos, em particular, uma abordagem dessa política externa que leva em conta um plano mais amplo, regional, incluindo a busca de aliados estratégicos ${ }^{12}$ e os contornos particulares que o confronto bipolar com a URSS adquiriu nas Américas, configurando o que Tanya Harmer qualificaria de "Guerra Fria interamericana". ${ }^{3}$

Se a ascensão do tema dos direitos humanos nos EUA é inegável, sua inserção na política externa não apenas foi conflituosa, como produziu resultados discutíveis. De Lyndon Johnson (1963-1969) a Jimmy Carter (1977-1981) a evolução é notável, porém também o é o refluxo desse movimento com o retorno do paradigma dos "falcôes" da Guerra Fria na administração de Ronald Reagan. Do outro lado da equação, os setores militares e da elite conservadora do Cone Sul, instalados no poder com o apoio político, econômico e por vezes operacional dos EUA, tinham sua agenda anticomunista própria, e pouca disposição em subordinar-se aos "vaivéns” da política estadunidense quando esta lhes era desfavorável.

Esse artigo examina esses dois polos em uma conjuntura de progressiva inserção dos direitos humanos no cálculo político da política externa estadunidense, com foco nos golpes de estado do Brasil (1964), do Chile (1973) e da Argentina (1976) ${ }^{14}$ e em alguns acontecimentos críticos que tensionaram as relaçóes entre os EUA e os governos do Cone Sul antes da pauta dos direitos humanos fazer sua entrada oficial na Casa Branca com Jimmy Carter, em 1977. O objetivo é contribuir para historicizar o dilema posto à política externa estadunidense entre a lógica da contrainsurgência e o discurso dos direitos humanos, observando como a categoria de "risco" desem-

\footnotetext{
${ }^{8}$ FICO, Carlos. O grande irmão: da operação Brother Sam aos anos de chumbo. Rio de Janeiro: Civilização Brasileira, 2008; NOVARO, Marcos. Cables secretos. Buenos Aires: Edhasa, 2011; KORNBLUH, Peter. The Pinochet File, op. cit.; SCHMIDLI, William Michael. The Fate of Freedom Elsewhere, op. cit.

${ }^{9}$ SIKKINK, Kathryn. Mixed Signals. Ithaca, NY: Cornell University Press, 2004.

${ }^{10}$ KEYS, Barbara J. Reclaiming American Virtue. Cambridge: Harvard University Press, 2014.

${ }^{11}$ SCHMITZ, David F. The United States and Right-wing Dictatorships, op. cit.

${ }^{12}$ SPEKTOR, Mathias. Kissinger e o Brasil. Rio de Janeiro: Zahar, 2009.

${ }^{13}$ HARMER, Tanya. Allende's Chile and the Inter-American Cold War. Chapel Hill: University of North Carolina Press, 2011, p. 1.

${ }^{14}$ A ditadura argentina considerada nesse artigo será a de 1976-1983. Sobre a anterior, ver FICO, Carlos. Os golpes de 1964 e 1966 no Brasil e na Argentina e o papel dos EUA. In: Anais do Seminário Internacional Ditadura e Democracia na América Latina: Balanço Histórico e Perspectivas. Rio de Janeiro: Fundação Getúlio Vargas, 2008, p. 53-76. v. 1. RAPOPORT, Mario; LAUFER, Rubén. Os EUA diante do Brasil e da Argentina: os golpes militares da década de 1960. Revista Brasileira de Política Internacional, v. 43, n. 1, p. 69-98, 2000.
} 
penhou um papel fundamental nas escolhas efetuadas. ${ }^{15}$ Parte-se de documentos provenientes de agências governamentais dos EUA, entretanto, evita-se a armadilha de tomar as influências em um sentido unidirecional buscando-se, ao contrário, pensar nas inter-relaçóes transnacionais do complexo cenário interamericano dos anos 1960-1970.

\section{Da reforma social à contrainsurgência}

A década de 1960 iniciou-se nos EUA com a posse de John Kennedy. Como lembra Diane Kunz, tanto ele quanto seu rival republicano, Richard Nixon, "posicionaram sua áspera retórica de Guerra Fria no centro da corrida presidencial". ${ }^{16}$ Para a América Latina, a administração Kennedy lançou a Aliança para o Progresso, projeto que previa reformas sociais e treinamento militar em contrainsurgência como pilares da estratégia estadunidense para evitar que a regiáo seguisse o exemplo da revolução cubana. O programa emperrou na "ineficiência administrativa"17 e esbarrou em obstáculos estruturais: extrema desigualdade social, concentração de renda, miséria e resistência das elites a operar mudanças..$^{18}$ Em 1964, avaliando a "revolução e a subversão na América Latina" em 21 países, a CIA reconhecia haver "uma crescente demanda popular por mudança radical nas condiçóes existentes - econômicas, sociais e políticas" ${ }^{\prime 19}$ e demonstrava sua incredulidade nos efeitos de uma reforma em curto prazo. Diante desse quadro, a política externa estadunidense rapidamente abandonaria o essencial do plano reformista do início da administração Kennedy para centrar-se na contenção do comunismo por outros meios: treinamento militar e policial em operaçôes de contrainsurgência e desenvolvimento econômico por intermédio da abertura do mercado aos investimentos externos privados. Em cinco anos de operação da Aliança para o Progresso, nove golpes militares foram deflagrados contra governos civis na regiáo. ${ }^{20}$ No caso do Brasil, essa guinada traduziu-se no reforço da base militar da embaixada dos EUA, com o envio, como adido militar, do coronel Vernon Walters, em julho de $1962 .{ }^{21}$

Nos anos que se seguiriam, as escolhas do governo estadunidense em matéria de apoio a regimes autoritários justificar-se-iam pelo famoso raciocínio expresso por John Kennedy

\footnotetext{
${ }^{15}$ Agradeço a Maud Chirio por sugerir essa formulação.

16 “(...) placed their harsh Cold War rhetoric at the center of the race for the presidency." KUNZ, Diane

B. (Ed.). The Diplomacy of the Crucial Decade. American Foreign Relations During the 1960. Nova York: Columbia University, 1994, p. 2.

${ }^{17}$ FICO, Carlos. O grande irmão: da operação Brother Sam aos anos de chumbo, op. cit., p. 34.

${ }^{18}$ WALKER, William O. Mixing the Sweet with the Sour: Kennedy, Johnson, and Latin America. In: KUNZ, Diane B. (Ed.). The diplomacy of the Crucial Decade. American Foreign Relations During the 1960, op. cit., p. 53.

19 “(...) a rising popular demand for radical change in existing conditions - economic, social, and political." CIA. Communist Potentialities in Latin America, 80/90-64, 19 August 1964 - Revolution and subversion in Latin America. Selected U.S. intelligence community estimative products, 1947-1987, p. 2.

${ }^{20}$ WALKER, William O. Mixing the Sweet with the Sour: Kennedy, Johnson, and Latin America, op. cit., p. 59.

${ }^{21}$ GASPARI, Elio. A ditadura envergonhada. São Paulo: Companhia das Letras, 2002, p. 57.
} 
em relação à República Dominicana e a Cuba: "em uma ordem de preferência decrescente: um regime democrático decente, uma continuação do regime [do tipo] de Trujillo ou um regime de Castro. Devemos mirar no primeiro, mas não podemos renunciar ao segundo até estarmos certos de poder evitar o terceiro.” ${ }^{22} \mathrm{Na}$ lógica do Departamento de Estado, essa distinção seria por diversas vezes acionada para justificar o apoio a figuras avaliadas como “moderadas", como Emílio Garrastazu Médici, ${ }^{23}$ no Brasil; Augusto Pinochet, ${ }^{24}$ no Chile; e Rafael Videla, ${ }^{25}$ na Argentina. Em um espectro político acirrado pelas tensóes da Guerra Fria e visto sob as lentes estadunidenses, esses nomes constituíam as escolhas consideradas mais razoáveis entre líderes civis reformistas e militares de extrema direita. Segundo análise da CIA, "A ordem tradicional e a ordem potencialmente democrática estão ambas sob agudo ataque, seja pelos ultranacionalistas radicais, seja pelos comunistas" ${ }^{26}$

Da desestabilização do presidente eleito João Goulart, iniciada durante a administração Kennedy, à tomada de poder pelos militares, concluída no início do governo de Lyndon Johnson, o golpe militar no Brasil de 1964 teve importante participaçáo dos EUA. O apoio consubstanciou-se no financiamento da oposição nas eleiçóes de 1962, no suporte a governadores críticos ao governo, na propaganda política, na organização de grupos contrários ao governo, no planejamento do golpe, ${ }^{27}$ na montagem da não deflagrada Operação Brother Sam, no pronto reconhecimento do governo militar recém-empossado e na generosa ajuda financeira oferecida no pós-golpe. A tomada do poder pelos militares no Brasil foi interpretada pela opinião pública estadunidense como uma defesa da democracia contra um ataque comunista. O Departamento de Estado orquestrou um esforço de desinformação junto à imprensa e ao Congresso, para assegurar que não prevalecesse uma visão negativa do evento e para que a participação dos EUA na empreitada permanecesse desconhecida. ${ }^{28}$ Quando iniciaram os expurgos de simpatizantes do governo de João Goulart e as violências contra os setores oposicionistas, incluindo prisóes ilegais, a diplomacia estadunidense teve de enfrentar um dilema que seria uma constante em sua política externa: dar sustentação

\footnotetext{
22 "In descending order of preference: a decent democratic regime, a continuation of the Trujillo regime or a Castro regime. We ought to aim at the first, but we really cannot renounce the second until we are sure that we can avoid the third." KENNEDY, John apud SCHMITZ, David F. The United States and Right-wing Dictatorships, op. cit., p. 4. Rafael Trujillo tomou o poder na República Dominicana em 1930, com ajuda dos EUA, e conduziu uma ditadura até ser assassinado em 1961.

${ }^{23}$ Precis of Brazil Program Analysis, 1970, Arquivo Nacional, CNV.0.RCE.00092000538201527/73. p. 8

${ }^{24}$ Augusto Pinochet Ugarte. Jan. 1975. NSA, CL01128.

${ }^{25}$ Telegrama. Videla's moderate line prevails. 29/04/1976. NSA, AR00209.

26 "Both the traditional order and the potential democratic order are under sharp attack by radical ultranationalist as well as by Communists." CIA. Communist Potentialities in Latin America, 80/90-64, p. 7.

${ }^{27}$ Carlos Fico dá indicaçôes detalhadas da coincidência das açôes dos golpistas com as linhas de ação propostas em plano de contingência elaborado pelo embaixador Lincoln Gordon. FICO, Carlos. O grande irmão: da operaçáo Brother Sam aos anos de chumbo, op. cit., p. 88-93.

${ }^{28}$ GREEN, James. Apesar de você, op. cit., p. 26. Ver também p. 72-80. Segundo o autor, quando houve, no ano seguinte, uma intervenção estadunidense na República Dominicana, 76\% dos entrevistados foram favoráveis à invasão. Ibidem, p. 105.
} 
ao aliado anticomunista, comprometendo a coerência de sua retórica democrática e legalista e arriscando-se a alimentar o antiamericanismo, ou distanciar-se do governo que ajudara a colocar no poder, enfraquecendo sua influência política no país. No caso brasileiro, como em outros, optou-se pela primeira alternativa.

Até o Ato Institucional no $n^{-5}$, raras tinham sido as vozes nos EUA que haviam se levantado para criticar o envolvimento do país no golpe. Com a nova medida, porém, a imprensa estadunidense começou a pressionar a Casa Branca para que se manifestasse contra o que considerava uma "total ditadura militar". ${ }^{29}$ Mesmo no seio do Departamento de Estado, a medida provocou certa comoção: telegrama para a embaixada no Brasil, assinado pelo então secretário do Estado Dean Rusk, demonstra plena consciência do alcance autoritário do Ato, assombro diante dos poderes discricionários que ele atribuía ao presidente e incredulidade sobre seu imperativo naquela conjuntura:

Não há como defender as arbitrariedades do AI-5 e os poderes que confere a Costa e Silva. Parece-nos que ele pode fazer quase qualquer coisa que desejar a praticamente qualquer pessoa no país (...). Parece-nos inverossímil que as que ameaças ao bem-estar do governo ou do país, ou a prevalência da subversão e da corrupção fossem de tal monta a autorizar a grave violação das restriçôes constitucionais e dos direitos políticos e civis ou que, sendo assim, não houvesse maneiras mais sábias, civilizadas e legais de lidar com elas. ${ }^{30}$

Não havia contudo muito o que fazer, dadas a pouca receptividade dos militares brasileiros a críticas e a improbabilidade de mudanças a curto prazo. Concretamente, o Departamento de Estado, refém de seu apoio ao regime, tentou evitar um desgaste com seu aliado. Esse "efeito colateral" da agressiva geopolítica anticomunista da potência mostra os limites de sua influência sobre os países aliados, assim como o receio de despertar brios nacionalistas que se interpusessem aos interesses dos EUA, conforme mostra um memorando sobre as perspectivas de sucessão presidencial, em 1969, após a morte de Costa e Silva: "Um período prolongado de instabilidade governamental ou uma mudança para um governo mais nacionalista teria grandes implicaçóes para o extenso programa de ajuda dos EUA ao Brasil e para o substancial investimento empresarial dos EUA no país."31

\footnotetext{
${ }^{29}$ Ibidem, p. 119.

30 "There is no arguing arbitrariness of IA-5 and powers it gives Costa e Silva. Looks to us that he can do almost anything he wishes to almost anyone in country (...). Seems almost incredible to us that threats to government or country's well being, or prevalence of subversion and corruption, were such as to warrant gross breaching of constitutional restraints and political and civil rights or that, if so, there weren't wiser, more civilized and lawful ways of dealing with them." NARA, 25/12/1968, RG 59, Central Files 1967-69, POL 23-9 BRAZ. Documento citado em GREEN, James. Apesar de você, op. cit., p. 152-153.

31 "A prolonged period of governmental instability or a change to a more nationalistic government would have major implications for the large US aid program in Brazil and for the substantial US business investment in the country." AN, CNV.0.RCE.00092003323201487/34
} 
A tortura era um tema particularmente sensível porque o governo brasileiro acreditava ser esse um instrumento essencial em sua luta contra os grupos dissidentes, no que era acompanhado pelos militares estadunidenses que ministravam treinamento de guerra antissubversiva para os latino-americanos e mesmo por alguns funcionários de alto nível do Departamento de Estado. Quando o embaixador dos EUA, Charles Elbrick, foi sequestrado em setembro de 1969, os militares da chamada linha-dura ficaram furiosos tanto com a displicência do embaixador com sua segurança quanto com o fato de o governo brasileiro ter aceitado todas as condições dos sequestradores. O telegrama da embaixada dos EUA do Rio de Janeiro sobre o impacto político do sequestro mostra que os funcionários estadunidenses tinham plena consciência de que o evento havia agravado as dissidências internas entre os militares e comenta que aqueles que se opunham à negociação com os sequestradores tinham achado humilhante barganhar com "terroristas". ${ }^{32}$ Assim, não parecia prudente pressionar excessivamente o governo brasileiro sobre a questão da tortura, ainda que o tema ganhasse espaço no âmbito doméstico estadunidense. Ademais, conforme os EUA atolavam-se na guerra do Vietnã, a retórica da defesa da democracia ia sendo progressivamente substituída pela do resguardo da estabilidade e do anticomunismo. ${ }^{33}$

\section{A política imperial e os direitos humanos}

Embora não tivesse particular interesse na América Latina — "No que nos diz respeito, ninguém está nem aí para a América Latina”, ${ }^{34}$ teria dito a um funcionário — - Richard Nixon notabilizou-se, entre outras coisas, por sua política na região. Empossado logo após a imposição do AI-5 no Brasil, o novo presidente não se deixou levar pelas críticas internacionais ao novo surto de autoritarismo no país. Ademais, Nixon não acreditava que a democracia do estilo estadunidense pudesse funcionar na América Latina. ${ }^{35}$ A ajuda econômica ao Brasil foi retomada e a proximidade restabelecida, com base no peso geopolítico do país, no anticomunismo compartilhado e no volume de investimentos das empresas estadunidenses. ${ }^{36}$

Naquele momento a urgência não era moderar a repressão política brasileira, e sim evitar a todo o custo que um declarado socialista vencesse as eleiçóes no Chile. Nixon e Kissinger assumiram o controle da política externa, transferindo parte considerável das atribuiçóes do Departamento de Estado ao Conselho de Segurança Nacional, que passou a ser o centro ope-

\footnotetext{
${ }^{32}$ Foreign Service of the United States of America: Political Impact of Kidnapping. 22/06/1970. AN, CNV. 0.RCE.00092000538201527/224.

${ }^{33}$ SCHMIDLI, William Michael. The Fate of Freedom Elsewhere. Human Rights and U.S. Cold War Policy Toward Argentina, op. cit., p. 42.

34 "Long as we've been in it, people don't give one damn about Latin America." NIXON, Richard apud SCHMIDLI, William Michael. The Fate of Freedom Elsewhere, op. cit., p. 43.

${ }^{35}$ Idem.

${ }^{36}$ FICO, Carlos. O grande irmão: da operação Brother Sam aos anos de chumbo, op. cit., p. 237.
} 
racional da tomada de decisóes em matéria de diplomacia, de defesa e de inteligência. ${ }^{37}$ Enquanto a nova administração republicana promovia uma histórica concentração de poderes, dossiês de denúncia montados por ex-presos políticos e familiares chegaram às mãos de ativistas religiosos, intelectuais brazilianistas e políticos, e, aos poucos, por meio de discursos, abaixo-assinados e outras demonstrações públicas foram ganhando repercussão.

Em vista da proliferação de denúncias a diplomacia estadunidense, preocupada com os efeitos dessa campanha internacional contra um de seus aliados, cuidadosamente levantou o assunto com militares brasileiros. Estes argumentavam que as alegações eram parte de uma campanha internacional orquestrada cujo intuito era desmoralizar o governo brasileiro, bordão que seria repetido à exaustão por seus congêneres no Chile e na Argentina. Um relatório enviado ao Departamento de Defesa estadunidense reproduz a réplica de um agente policial brasileiro, em festa promovida pelo programa de Segurança Pública da Usaid em 1970, sobre o espinhoso tema, contendo implícito o conhecimento de métodos ensinados pelos próprios estadunidenses na América Latina e aplicados na guerra do Vietná, convocando ao silêncio cúmplice: "Somos um país civilizado e os métodos de interrogatório usados para conseguir informações seguem os padróes que vocês americanos também usam" ${ }^{38}$

Nixon e Kissinger, enquanto isso, colocavam as máquinas do Departamento de Estado e da CIA em funcionamento para preparar a derrubada do presidente chileno Salvador Allende. Peter Kornbluh assinala que a ação da CIA não era consensual. Não havia no Chile investimentos de "interesse nacional vital" e a eleição de Allende não consistia risco para a segurança nacional dos EUA. Além disso, a comunidade de inteligência tinha plena consciência da possibilidade de o país se tornar "refém" dos setores apoiados. Outro argumento de peso levantado foi o de repetir a desastrada estratégia adotada com Cuba, que levou a ilha a associar-se ao campo soviético. ${ }^{39}$ Por outro lado, como lembra Tanya Harmer, a eleição de Allende demonstrou inequivocamente a deterioração da influência dos EUA na América Latina, despertando o temor de que a potência viesse a perder sua primordial e tradicional área de influência. ${ }^{40}$ Após fracassada tentativa de evitar que Allende tomasse posse, Kissinger e sua equipe organizaram uma robusta estratégia com o intuito de tornar o país tão instável que um golpe militar seria bem-vindo. $\mathrm{O}$ plano incluía a decidida participação do setor privado e previa operaçóes encobertas nos campos político, econômico, midiático e militar, diversas das quais lembravam as que haviam sido utilizadas no Brasil na década anterior contra o governo João Goulart.

Convém notar que a estratégia adotada em relação ao Chile, assim como ocorrera no Brasil, foi a de financiar e dar suporte a atores nativos do próprio país contrários ao governo

\footnotetext{
${ }^{37}$ Ibidem, p. II.

38 "We are a civilized country and the interrogation methods used to gain information follow the standard practices which you Americans also use." Department of Defense Intelligence Information Report: Police official comments on torture. 23/4/1970. AN. CNV.0.RCE.00092000538201527/13.

${ }^{39}$ KORNBLUH, Peter. The Pinochet File, op. cit., p. 112.

${ }^{40}$ HARMER, Tanya. Allende's Chile and the Inter-American Cold War, op. cit., p. 9.
} 
“indesejável”. O memorando de conversação que registra a reunião da alta cúpula do governo estadunidense para discutir o que fazer diante da eleição chilena mostra que o subsecretário de Estado, John N. Irwin II, formula o problema da seguinte maneira: "A questão é como melhor influenciar as forças internas para criar as condiçóes para mudanças." ${ }^{\text {"11 }} \mathrm{O}$ comentário é expressivo, pois indica as restriçóes impostas ao poder imperial dos EUA, que não tinham legitimidade para impedir, unilateral e abertamente, que um inimigo político assumisse o poder. Demonstra, ainda, que havia uma confluência de agendas entre a política externa dos EUA e parcela importante das elites latino-americanas. Não foi necessário que a força-tarefa da Operação Brother Sam agisse em favor do golpe brasileiro, nem que o plano contingencial previsto caso o golpe chileno falhasse fosse posto em prática: "enquanto os políticos estadunidenses hesitavam e aguardavam o curso dos eventos, foram os líderes militares chilenos que deflagraram o golpe com a ajuda dos simpáticos amigos brasileiros, não os EUA." ${ }^{2} 2$ Mas é extremamente significativo que essas alternativas tenham existido. Assim, mensurar de maneira precisa o papel dos EUA na deflagração e sustentação das ditaduras militares no Cone Sul implica evitar enxergar os atores internos como meros peóes em um xadrez internacional. Ao mesmo tempo, reconhecer que as relaçóes entre os EUA e as ditaduras militares não foram uniformemente estreitas no tempo e que houve fissuras e desacordos não invalida o fato de que o investimento nessas ditaduras foi considerável e provavelmente decisivo para seu sucesso e sua duração.

A fala do presidente Nixon em reunião de cúpula de novembro de 1970 aponta a estratégia de apostar nos setores militares, junto aos quais a diplomacia estadunidense vinha trabalhando desde a administração Kennedy com o intuito de construir uma visão em comum: "Vamos deixar de lado o que os países realmente democráticos da América Latina dizem — o jogo está no Brasil e na Argentina. (...) São centros de poder sujeitos a nossa influência." ${ }^{43}$ Explicita ainda o real perigo vislumbrado no êxito de Allende em termos expressivamente distantes da retórica apocalíptica contra os supostos riscos de ver implantado um "totalitarismo comunista": "Nossa maior preocupação no Chile é a perspectiva de que ele possa consolidar-se e de que projete seu sucesso no mundo. (...) Se deixarmos os líderes potenciais da América do Sul pensarem que podem fazer como o Chile e ganhar do dois lados, estaremos perdidos." 44

\footnotetext{
41 "The question is how best to influence the internal forces to create the conditions for change." Memorandum of conversation. NSC meeting - Chile. 6/11/1970. NSA, CL00309, p. 3.

42 "While U.S. policy makers hesitated and waited in the wings for events to take their course, it was Chilean military leaders who launched the coup with the help of sympathetic Brazilian friends, not the United States." HARMER, Tanya. Allende's Chile and the Inter-American Cold War, op. cit., p. 16. Sobre o plano contingencial, ver KORNBLUH, Peter. The Pinochet File, op. cit., p. 112.

43 "Let's not think about what the really democratic countries in Latin America say - the game is in Brazil and Argentina. (...) They are power centers subject to our influence." Memorandum of conversation. NSC meeting - Chile. 6/11/1970. NSA, CL00309, p. 4.

44 "Our main concern in Chile is the prospect that he can consolidate himself and the picture projected to the world be his success. (...) If we let the potential leaders in South America think they can move like Chile and have it both ways, we will be in trouble." Idem.
} 
A perspectiva de Nixon sobre a América Latina é bem descrita por Elio Gaspari:

Vista da Casa Branca, a América Latina ia de mal a pior. Noves fora Fidel Castro, o Chile era governado por um socialista, o Peru e a Bolívia por generais nacionalistas. No Uruguai o terrorismo Tupamaro parecia o prelúdio de um governo de esquerda. Náo só a ditadura brasileira era simpática ao governo do presidente Richard Nixon, mas também o governo Nixon mostrava-se simpático às ditaduras em geral. ${ }^{45}$

Devido à importância regional do Brasil e sua hostilidade ao presidente eleito no Chile, ${ }^{46}$ a administraçáo Nixon chegou a aventar um canal privilegiado com Garrastazu Médici, primeiro general latino-americano recebido por ele, em dezembro de $1971 .{ }^{47}$ Do outro lado do espectro político, ativistas brasileiros e estadunidenses logravam fazer com que os ecos de seus relatórios sobre a violência repressiva no Brasil pós-AI-5 chegassem ao Congresso do EUA. Em 1970, o senador Edward Kennedy fez um pronunciamento a respeito da política externa de seu país em relação ao Brasil: "Ficamos em silêncio enquanto prisioneiros políticos são torturados no Brasil."’48 No ano seguinte, o senador democrata Frank Church, presidente da Subcomissão de Assuntos do Hemisfério Ocidental, promoveu uma audiência para discutir o programa de segurança pública responsável pelo treinamento da polícia brasileira. ${ }^{49}$

A enérgica política externa da administração Nixon, porém, não foi sensibilizada por esses setores progressistas do Congresso estadunidense. Sua administraçáo levou ao paroxismo o apoio a ditaduras de direita pelo mundo e ficaria particularmente marcada pelo golpe militar no Chile. Poucos dias após a derrubada de Allende, Kissinger, promovido a secretário de Estado, transmitiria por canais privados as boas-vindas aos militares chilenos. Porém, na audiência de confirmação no novo posto pelo Comitê de Relaçôes Exteriores do Senado, explicou a política oficial de "neutralidade" diante do novo governo chileno: "Tomamos a decisão de que não diríamos nada que indicasse nem apoio, nem oposição - que evitaríamos o que fizemos no Brasil em 1964, quando nos precipitamos ao reconhecer o governo." 50

\footnotetext{
${ }^{45}$ GASPARI, Elio. A ditadura escancarada. São Paulo: Companhia das Letras, 2002, p. 339.

${ }^{46}$ HARMER, Tanya. Allende's Chile and the Inter-American Cold War, op. cit.; PADRÓS, Enrique Serra; SIMOES, Silvia. A ditadura brasileira e o golpe de Estado chileno. Outros Tempos, v. 10, p. 233-261, 2013.

${ }^{47} \mathrm{O}$ projeto náo vingou. SPEKTOR, Mathias. Kissinger e o Brasil, op. cit.

48 "We stand silent while political prisoners are tortured in Brazil." KENNEDY, Edward apud SIKKINK, Kathryn. Mixed Signals, op. cit., p. 58.

${ }^{49}$ Ibidem, p. 61. Terminou em 1972, porém a ajuda militar e econômica ao Brasil seria suspensa apenas na administração Carter. Ver HUGGINS, Martha. Polícia e política. São Paulo: Cortez, 1998; MOTTA, Rodrigo Patto Sá. Modernizando a repressão. A Usaid e a polícia brasileira. Revista Brasileira de História, v. 30, n. 59, p. 237-266, jun. 2010.

50 "We took the decision that we would not say anything that indicated either support or opposition — that we would avoid what we had done in Brazil in 1964 where we rushed out by recognizing the government." KISSINGER, Henry apud KORNBLUH, Peter. The Pinochet File, op. cit., p. 209.
} 
No ano seguinte, o coronel Manuel Contreras viajou aos EUA, a serviço de Pinochet, e ali encontrou-se com Vernon Walters, o adido militar que ajudara a articular o golpe no Brasil e na época era vice-diretor da CIA. Contreras, que tinha íntimos contatos com a CIA e chegou a ser pago pela agência, foi a figura central da criação da polícia política chilena, a Dirección de Inteligencia Nacional, que respondia apenas à autoridade do próprio Augusto Pinochet. ${ }^{51}$ Nixon e Kissinger seriam cúmplices da onda repressiva que se seguiu ao golpe e chocou a opiniấo pública internacional, fornecendo vultosa ajuda financeira e militar e oferecendo garantias a Pinochet de que poderia contar com o suporte dos EUA.

Outro movimento, porém, organizava-se na direção inversa e, se não alterou o curso dessa política, ao menos representou um obstáculo a ser considerado. Desde o final dos anos 1960 a insatisfaçáo com a guerra do Vietná, cada vez mais percebida como um movimento de libertação nacional e menos como uma ameaça à estabilidade do bloco ocidental, chamou a atenção de alguns setores da sociedade civil estadunidense para a política externa de seu país. No que diz respeito às ditaduras do Cone Sul, o Brasil, após o decreto do AI-5 em 1968, abriu o caminho: "O protesto contra a ditadura brasileira no final dos anos 1960 estava entre as primeiras instâncias da nascente defesa dos direitos humanos na América Latina, se não do mundo." ${ }^{52}$ De um discurso centrado na denúncia da tortura, passou-se progressivamente a uma retórica de direitos humanos, adotada por religiosos no Brasil e nos EUA e pela Anistia Internacional. ${ }^{53}$ Porém o turning point do ativismo transacional pelos direitos humanos foi o golpe militar chileno, com sua massiva onda de execuçôes sumárias, prisóes e torturas inaugurada pelo impressionante bombardeamento do Palácio de la Moneda e a destruição do experimento de Allende de implantar o socialismo por uma via pacífica. As primeiras organizaçôes de direitos humanos do pós-guerra na América Latina, segundo Samantha Viz Quadrat, surgiriam após o golpe chileno, ainda que as discussões para a criação de algumas delas tenha antecedido o golpe ${ }^{54}$ De fato, a comoção diante da intervenção militar foi intensa: "A reação internacional ao golpe foi imediata, generalizada e esmagadoramente condenatória. (...) O dedo estava inevitavelmente apontado para o governo dos EUA." 55

${ }^{51}$ DINGUES, John. Os anos do Condor. Uma década de terrorismo internacional no Cone Sul. São Paulo: Companhia das Letras, 2004, p. 112-113.

52 "Protest against the Brazilian dictatorship in the late 1960s was among the first instances of nascent human rights advocacy in Latin America, if not the world." KELLY, Patrick William. "Magic words". The Advent of Transnational Human Rights Activism in Latin America's Southern Cone in the Long 1970s. In: ECKEL, Jan; MOYN, Samuel (Eds.). The Breakthrough. Human Rights in the 1970's, op. cit., p. 89.

${ }^{53}$ Ibidem, p. 91.

${ }^{4}$ A autora cita diversas entidades criadas na Argentina, no Chile e no Brasil nos anos 1970. QUADRAT, Samantha Viz. A emergência do tema dos direitos humanos na América Latina. In: FICO, Carlos; FERREIRA, Marieta de Moraes; ARAÚJO, Maria Paula; QUADRAT, Samantha Viz (Orgs.) Ditadura e democracia na América Latina. Balanço histórico e perspectivas. Rio de Janeiro: Fundação Getulio Vargas, 2008. p. 378-380. 55 "International reaction to the coup was immediate, widespread, and overwhelmingly condemnatory. (...) Inevitably, finger-pointing was directed at the U.S. government." KORNBLUH, Peter. The Pinochet File, op. cit., p. 113. 
Se os precursores dos esforços em alterar os rumos da política externa foram parlamentares progressistas, como o deputado Donald Fraser ou os senadores Frank Church e Edward Kennedy, a coalizão incorporou parlamentares conservadores cuja agenda centrava-se na denúncia às violaçôes aos direitos humanos cometidas em países socialistas.

Uma coalizão inusual de liberais e conservadores deu suporte à legislação de direitos humanos. No Congresso, votos a favor de cortar a ajuda a violadores vieram de liberais dedicados a reduzir as ligaçóes estadunidenses com regimes repressivos, de anticomunistas que apoiavam políticas de direitos humanos contra regimes comunistas e de conservadores com interesse em reduzir os gastos dos EUA com ajuda externa. ${ }^{56}$

Desse modo, embora o movimento pelos direitos humanos fosse o principal canal para o qual convergiram variadas formas de militância progressista, a resultante de sua polissemia dava forma a uma sensibilidade mais moral do que política, antes voltada a indivíduos vitimizados pela violência do Estado do que a grupos sociais reivindicando direitos sociais, econômicos e políticos. ${ }^{57}$

Os EUA viveram uma acerba disputa entre o Capitólio e a Casa Branca pelo controle da política externa: "Buscando manter a primazia do Executivo na formulação da política externa, Kissinger opunha-se particularmente à legislação do Congresso vinculando açóes dos EUA na arena internacional a consideraçôes de direitos humanos." ${ }^{58} \mathrm{O}$ ativismo do Congresso assumiu essencialmente duas formas. A primeira foi a promoção de audiências organizadas por senadores progressistas, reunindo funcionários do governo, advogados, exilados, intelectuais e ativistas de ONGs, para avaliar os efeitos nefastos do apoio a ditaduras militares de direita e elaborar diretrizes para construir uma política externa compatível com o respeito aos direitos humanos. O deputado Donald Fraser iniciou em agosto de 1973 - portanto logo antes do golpe no Chile - um esforço que em cinco anos levou a 150 audiências sobre o tema, nas quais a gramática dos direitos humanos estava presente. ${ }^{59}$

\footnotetext{
56 "An unusual coalition of liberals and conservatives supported human rights legislation. In Congress, votes in favor of cutting assistance to violators came from liberals dedicated to reducing American ties to repressive regimes, from anticommunists who supported human rights policy against communist regimes, and from conservatives with a more general interest in reducing U.S. expenditures on foreign aid." SIKKINK, Kathryn. Mixed Signals, op. cit., p. 71.

${ }^{57}$ KELLY, Patrick William. "Magic Words". The Advent of Transnational Human Rights Activism in Latin America's Southern Cone in the Long 1970s, op. cit.

58 "Seeking to maintain executive branch primacy in the formulation of foreign policy, Kissinger was particularly opposed to congressional legislation binding U.S. actions in the international arena to human rights considerations." SCHMIDLI, William Michael. The Fate of Freedom Elsewhere. Human Rights and U.S. Cold War Policy Toward Argentina, op. cit., p. 66.

${ }^{59}$ Por esse termo entendo, seguindo Patrick William Kelly, um conjunto de expressóes e conceitos empregando uma linguagem versátil e despolitizada que apela ao aspecto moral da violência praticada pelo Estado contra seus cidadãos, em uma abordagem que busca superar clivagens ideológicas de esquerda/direita e concentra-se em direitos civis e políticos em detrimento de um programa de mudança social radical.
} 
A segunda foi a elaboração de leis que criassem obstáculos à ajuda econômica e militar dos EUA a países que promovessem violência sistemática contra seus cidadãos. Inicialmente, essas leis incidiram em relaçóes bilaterais específicas: "Nesses primeiros debates (...) não havia uma visão geral alternativa de políticas ou de doutrinas que guiassem a política externa."60 A partir de setembro de 1975, porém, a emenda proposta pelo deputado Tom Harkin para o Ato de Assistência Internacional passou a prever a negaçáo de ajuda para países envolvidos em violaçôes massivas dos direitos humanos, incluindo a questâo em quase todas as decisóes de assistência externa. A medida levou Henry Kissinger a instruir as embaixadas no sentido de "responder prontamente em casos de direitos humanos envolvendo cidadãos dos EUA para evitar publicidade negativa". ${ }^{61}$ No Brasil, o presidente Ernesto Geisel queixou-se de que os EUA encontravam-se praticamente submetidos a "uma ditadura do Legislativo". ${ }^{2}$

Passado o caso Watergate, que levou à renúncia de Nixon em 1974, a administração de Gerald Ford fundamentalmente manteve a política de seu antecessor e buscou contornar os obstáculos criados pela nova legislação. No âmbito do Departamento de Estado, a questão dos direitos humanos era de ordem pragmática: com uma agenda importante de interesses comuns, o tema era evocado simultaneamente como um empecilho para uma relaçáo bilateral mais fluida, uma vez que obstruía a ajuda econômica e militar, e como um ponto sensível, que poderia ferir suscetibilidades diplomáticas. Cientes da complexidade da situaçáo brasileira, com Geisel tentando assegurar o controle da oposição e ao mesmo tempo evitar que a linha-dura pusesse à prova seu projeto de distensão, era preciso encontrar um equilíbrio entre dar apoio ao importante aliado sul-americano e expressar preocupaçóes com os "excessos" da repressão política. O memorando preparando um encontro do subsecretário de Estado para Assuntos Interamericanos, William D. Rogers, com João Augusto de Araújo Castro, embaixador brasileiro nos EUA, em junho de 1975, expressa a dificuldade:

Contudo, diante da forte resistência interna à liberalizaçáo política por parte de forças poderosas no interior do governo militar, esses passos têm sido lentos e, em geral, os controles rígidos, assim como abusos (prisōes arbitrárias, tortura), continuam. No passado, tratamos discretamente esses temas com funcionários brasileiros, mas a nova ênfase das disposiçóes legislativas vinculando consideraçôes de direitos humanos à assistência econômica e militar torna necessário inserir novamente algumas referências cuidadosas a essa delicada questão em nossas negociaçôes com certos funcionários do governo brasileiro. ${ }^{63}$

${ }^{60}$ "In these early debates, (...) No general vision of alternative policies or doctrines guided foreign policy." SIKKINK, Kathryn. Mixed Signals, op. cit., p. 64.

${ }^{61}$ "(...) respond quickly to human rights cases involving U.S. citizens to avoid unfavorable publicity." SCHMIDLI, William Michael. The Fate of Freedom Elsewhere. Human Rights and U.S. Cold War Policy Toward Argentina, op. cit., p. 68.

${ }^{62}$ GEISEL, Ernesto apud GASPARI, Elio. A ditadura encurralada. São Paulo: Companhia das Letras, 2004, p. 25. 63 "Nonetheless, in the face of strong internal resistance to political liberalization by powerful forces within the military and the government, these steps have been slow, and generally tight controls as well as abuses 
No Chile, a situação era ainda mais explosiva, pois o país, há pouco lançado numa ditadura militar, estava longe de arrefecer seus ânimos repressivos e, ao contrário, ocupava-se em estender suas capacidades articulando a Operação Condor. Quando Kissinger enviou às embaixadas do Cone Sul, em agosto de 1976, um telegrama instruindo os embaixadores a levantarem junto às mais altas autoridades dos países em que serviam a preocupação dos EUA com a repercussão negativa das operações internacionais e ilegais da Condor, o embaixador no Chile, David Popper, viveu um dilema que é bastante representativo das relações dos EUA com as ditaduras do Cone Sul. Um dos funcionários da embaixada, explicou a tensão nos seguintes termos:

(...) se fizermos isso, poderemos esquecer o canal entre o embaixador e Pinochet. Seria o fim da comunicação. O embaixador será boicotado, e quanto aos outros 250 itens que o Departamento de Estado deseja que levemos aos níveis mais elevados do governo, não seremos capazes de fazer nada. O embaixador estaria queimado. ${ }^{64}$

Diante da situação, decidiu-se aguardar novas instruções, que vieram semanas mais tarde, indicando o cancelamento das orientaçóes anteriores. Poucas horas depois, em 21 de setembro de 1976, Orlando Letelier e Ronie Moffit foram assassinados em Washington em um ataque da Operação Condor perpetrado pelos agentes da Dirección de Inteligencia Nacional (Dina) e ordenado diretamente por Augusto Pinochet, contrariado pelo ativismo do político ligado a Allende na denúncia das violências cometidas pela ditadura chilena. ${ }^{65}$ $\mathrm{O}$ atentado, ocorrido na capital dos EUA, teria implicações importantes nas relações entre os EUA e o Chile durante a administração de Carter e levaria à substituição da Dina pelo Centro Nacional de Informaciones, em agosto do ano seguinte.

\section{Crise e oportunidade}

Enquanto o Brasil entrava em sua "distensão lenta, gradual e segura” e avançava em passos trôpegos rumo a uma abertura política e o Chile estava em plena campanha repressiva, a Argentina vivia um pesadelo político. Kubish, funcionário da Secretaria de Estado dos Assuntos Interamericanos, descrevia o país em meados de 1974 como um "mosaico de dis-

(arbitrary arrest, torture) remain. We have discreetly raised these issues with Brazilian officials in the past, but the new emphasis and legislative provisions linking human rights considerations to military and economic assistance make it necessary to again insert some careful references to this delicate question in our dealings with selected GOB officials." Your meeting with Brazilian Ambassador Araujo Castro. 12/6/1975. Arquivo Nacional, CNV.0.RCE.00092000538201527/297.

${ }^{64}$ Apud DINGUES, John. Os anos do Condor. Uma década de terrorismo internacional no Cone Sul, op. cit., p. 275-6.

${ }^{65}$ A esse respeito, ver NSA, EBB 560. 
córdia política, econômica e social". ${ }^{66}$ A ação de diversos grupos "terroristas" náo significava uma ameaça direta ao governo de Perón. Todavia, tensionava sobremaneira a situação, com seus atentados e sequestros: "A inabilidade do governo de esmagar os terroristas agrava o mal-estar" ${ }^{67}$ Porém, se os interesses dos EUA ressentiam-se desse quadro, havia que agir com cuidado, devido ao nacionalismo argentino. Além disso, avaliava-se que

Os meios pelos quais o governo argentino está suprimindo os terroristas criarão sérios problemas para os EUA se formos identificados com eles. (...) Qualquer ligação, não importa o quão tênue seja, entre os EUA e essas organizaçóes semilegais, poderia ter sérias repercussóes. ${ }^{68}$

Para Marcos Novaro, a postura dos EUA em relação ao golpe militar que se seguiria teve como um de seus fatores decisivos a preocupação em evitar os "erros" cometidos com o Chile e o Uruguai. Em sua perspectiva, houve uma aprendizagem com experiências passadas que não se queria ver repetidas e mesmo o desenvolvimento de uma nova sensibilidade:

(...) contra a ideia de que as denúncias por violaçóes aos direitos humanos na região não preocupavam o Departamento de Estado até 1977, nem em geral à administração Ford, adverte-se em vários funcionários-chave da administração republicana uma séria inquietude por não repetir a experiência chilena. ${ }^{69}$

Apesar do que Peter Kornbluh chama de "síndrome chilena", a julgar pelo decidido apoio que os militares argentinos obtiveram de Kissinger e, em um primeiro momento, do embaixador, parece mais adequado atribuir a atitude estadunidense à diferença do quadro que se apresentava. Havia uma instabilidade política que implicava possíveis riscos nos negócios, contudo, a avaliação corrente da embaixada era a de que os grupos da esquerda armada não significavam uma ameaça real ao país em termos da vitória de um projeto revolucionário. Os guerrilheiros estavam sendo duramente combatidos, seja pelas organizaçóes de extrema-direita e paramilitares, como a Triple $A$, seja pelas próprias forças do Estado. Embora não estivesse conseguindo controlar a situação, o governo tomou medidas que não davam margem a críticas pelos anticomunistas: militarização do Estado e instituição de leis

\footnotetext{
66 “(...) mosaic of political, economic and social discord." Contingency paper for Argentina. STATE 142499, 02/07/1974. p. 1.

67 "The inability of the government to crush the terrorists compounds the uneasiness." Ibidem, p. 3-4.

68 "The means by which the Argentine government is suppressing the terrorists would create serious problems for the U.S. if we become identified with them. (...) Any linkage, no matter how tenuous, between the U.S. and these quasi-legal organizations could have serious repercussions". Ibdem, p. 4.

${ }^{69}$ “(...) contra la idea de que las denuncias por violaciones a los derechos humanos en la región no preocupan al Departamento de Estado hasta 1977, ni en general a la administración Ford, se advierte en varios funcionarios clave de la administración republicana una seria inquietud por no repetir la experiencia chilena." NOVARO, Marcos. Cables secretos, op. cit., p. 26.
} 
de exceçáo, como o estado de sítio proclamado em $1974 .{ }^{70}$ A censura que o Departamento de Estado fazia em relação ao governo de Maria Estela Perón era de fraqueza, característica considerada muito menos grave que o sindicalismo nacionalista de João Goulart ou o socialismo de Salvador Allende. Por fim, naquele momento, havia ditaduras militares no Paraguai, no Brasil, no Chile, no Uruguai, na Bolívia e no Peru, portanto o "efeito dominó", tão evocado no caso do Chile, era mais do que improvável na situação da Argentina. Além disso, embora Novaro tenha razão quando argumenta que funcionários-chave do Departamento de Estado inquietavam-se com um apoio acrítico à política repressiva argentina, a postura de adesão do Executivo, mobilizada pelo feroz anticomunismo de Kissinger, não se alterou significativamente antes da posse de Jimmy Carter, em 1977.

O embaixador dos EUA, Robert C. Hill, descrito por William Schmidli como "um inveterado cold warrior que denunciava tanto a administraçáo Kennedy quanto a Johnson por inépcia diplomática e frouxidão na batalha contra o comunismo", ${ }^{71}$ não desconsiderava a possibilidade de uma solução civil, porém acreditava que o vácuo de poder provavelmente levaria os militares ao poder, por serem a força mais unificada e autoconfiante. Acreditando que as forças armadas apenas assumiriam o poder como um último recurso, previa que tomariam medidas econômicas de austeridade e para isso teriam de usar "máo pesada" para impor ordem: "há uma questão aberta sobre se, no final das contas, teriam ou não estômago para tomar as medidas repressivas contra os trabalhadores, caso estes se rebelem contra as medidas de austeridade." ${ }^{72}$ Conquanto reconhecesse que não havia muito o que os EUA pudessem fazer para decidir o futuro da Argentina, alertava para a oportunidade que a situação abria, provavelmente significando a possibilidade de ver instalados, no governo da $\mathrm{Ar}$ gentina, militares "moderados", anticomunistas e simpáticos aos EUA, que trariam ordem e segurança para os investimentos estadunidenses e que comporiam com a política hemisférica de seu país em instâncias como a Organização dos Estados Americanos (OEA).

Durante a preparação do golpe, militares argentinos iniciaram consultas junto à embaixada estadunidense, preocupados em contornar a crítica internacional enfrentada pelo Chile e pelo Uruguai no campo dos direitos humanos. ${ }^{73} \mathrm{O}$ almirante Emílio Eduardo Massera, buscando o apoio dos EUA para o futuro governo, explicou que os militares teriam de intervir para evitar um caos total, mas que o combate à subversão seria efetuado por meios legais,

\footnotetext{
${ }^{70}$ FRANCO, Marina; IGLESIAS, Mariana. El estado de excepción en Uruguay y Argentina. Revista de História Comparada, Rio de Janeiro, v. 5, n. 1, 2011, p. 106.

71 "(...) an inveterate cold warrior, denouncing both the Kennedy and Johnson regimes for diplomatic ineptitude and laxity in the battle against communism." SCHMIDLI, William Michael. The Fate of Freedom Elsewhere. Human Rights and U.S. Cold War Policy Toward Argentina, op. cit., p. 45.

72 "There is an open question as to whether or not they would in the final analysis have the stomach to take strong repressive measures against Labor should the latter rebel against austerity measures." Contingency paper for Argentina. STATE 142499, 2/7/1974, p. 10.

${ }_{73}$ Cabo. Military Take Cognizance of Human Rights Issue. 16/2/1976, NSA, AR00170.
} 
evitando o exemplo de Pinochet. ${ }^{74}$ Enquanto o embaixador enaltecia o caráter moderado e civilizado da tomada de poder pelos militares, ${ }^{75}$ o subsecretário de Estado para Assuntos Interamericanos, William D. Rogers, advertia Kissinger de que o governo argentino provavelmente pediria ajuda, mas que era preciso manter prudente distância dos golpistas. Em uma predição que se demonstrou muito mais precisa do que a de Hill, acreditava que a repressão seria dura não apenas com os "terroristas", mas também com outros dissidentes. A posição de Kissinger era a de que era necessário fazer um gesto de boa vontade, ainda que náo necessariamente público. ${ }^{76}$ Em meados de junho de 1976, ficou claro que o "banho de sangue" previsto por Rogers estava ocorrendo e que eram falsas as alegaçôes sobre a responsabilidade das açóes repressivas ilegais não ser das próprias forças de segurança do país. O conselheiro político da embaixada, Maxwell Chaplin, concluiu que os sequestros e os assassinatos estavam sendo cometidos por forças de segurança, ou ao menos com a anuência destas, e que havia uma coordenação das forças do Cone Sul para combater o que consideravam subversão. ${ }^{77}$

$\mathrm{Na}$ assembleia geral da OEA, em Santiago do Chile, a postura de Kissinger refletiu as tensóes do momento. Seu assessor, preocupado com as repercussões internacionais da repressão política no Chile, o advertiu: "O problema dos direitos humanos no Chile é central, não apenas para o Congresso e a opiniāo pública, mas para nossas relaçóes como um todo."78 Obrigado a proferir um discurso em defesa dos direitos humanos, como resultado das pressóes do Congresso estadunidense e mesmo de setores do Executivo, o Secretário de Estado justificou a Pinochet, em conversa reservada, que limitar-se-ia a tocar no tema de maneira genérica. Declarando sua simpatia pela política praticada pela ditadura chilena, explicitou que se opunha à restrição de ajuda econômica para o Chile: "Minha avaliação é que vocês são uma vítima de todos os grupos de esquerda do mundo e que seu maior pecado foi ter derrubado um governo que estava se tornando comunista. Mas temos um problema prático que temos de levar em conta." ${ }^{79}$ Em seu contato com o almirante argentino César Augusto Guzzetti, que lhe pediu apoio nos campos da segurança interna e econômico, Kissinger demonstrou solidariedade, prometendo usar sua influência no setor privado para contornar as medidas do Congresso. Alertou-o, entretanto, sobre a necessidade de resolver o "problema” rapidamente e voltar em seguida a procedimentos normais para evitar o isolamento internacional em que o Chile se encontrava. ${ }^{80}$

\footnotetext{
${ }^{74}$ Telegrama. Ambassadors conversation with admiral Massera, 16/3/1976, NSA, AR00195.

${ }^{75}$ Telegrama. Videla's moderate line prevails. 29/4/1976. NSA, AR00209.

${ }^{76}$ Staff Meeting Transcripts. Secretary of State Henry Kissinger, Chairman, Secret. 26/3/1975. NSA. EBB. On 30th anniversary of Argentine coup.

${ }^{77}$ Cabo. Aftermath of kidnapping of refugees in Buenos Aires. 15/6/1976, NSA, AR00300.

78 "The problem of human rights in Chile is central, not only to the Congress and the public but for our relations as a whole." Memorando. Overall objectives for your visit to Santiago. 26/5/1976, NSA, CL01418. 79 "My evaluation is that you are a victim of all left-wing groups around the world and that our greatest sin was that you overthrew a government which was going Communist. But we have a practical problem we have to take into account." Memorando of conversation. U.S.-Chile relations. 8/6/1976. NSA, CL01429.

${ }^{80}$ Memorando of conversation. Henry Kissinger's meeting with admiral Guzzetti. 10/6/1976. NSA, AR00291.
} 
A cúpula militar argentina recebeu informaçóes incongruentes sobre a postura dos EUA em relação aos direitos humanos: enquanto o embaixador Hill insistia em pressioná-los para que adotassem o controle da guerrilha por vias legais, o subsecretário de Estado para a América Latina, Harry Shlaudeman, justificou a preocupação da opinião pública estadunidense como um traço pueril: "O problema é que os EUA são um país idealista e moral e seus cidadãos têm grande dificuldade de compreender o tipo de problema que a Argentina está enfrentando hoje. Há uma tendência a aplicar nossos padróes morais aos outros países." ${ }^{81} \mathrm{O}$ próprio Secretário de Estado reforçava essa visão, ao afirmar que a opinião pública não tinha a devida dimensão sobre a natureza do problema terrorista enfrentado pela Argentina. Entre as duas posturas conflitantes, o governo argentino naturalmente elegeu a instância hierárquica superior como sendo aquela que representava os ditames de Washington.

Dentro do Departamento de Estado, em meio a discordâncias entre os diferentes graus de hierarquia, a posição que parece ter prevalecido de modo mais generalizado foi aquela descrita pelo conselheiro político da embaixada, Maxwell Chaplin. Em extenso relatório sobre os direitos humanos na Argentina, Chaplin relativizou a questão da violência política ao situá-la no contexto argentino: "Terrorismo e contraterrorismo regularmente jogavam corpos nas ruas bem antes do golpe militar." ${ }^{2}$ Mencionou "abusos" e "excessos" atribuídos a diversos fatores, tais como a falta de coordenação e autonomia operativa dos órgãos repressivos, a importância da ameaça terrorista, a necessidade de contar com as forças de segurança para combater essa ameaça e as divisóes internas do governo militar. Visto como excessivamente moderado por outros militares que se opunham a seu programa econômico, ou à abertura que pretendia oferecer a setores civis, Rafael Videla precisava consolidar-se no poder antes de comprar briga com grupos envolvidos na repressão: "Porque a maioria dos observadores está convencida de que, se Videla fosse posto de lado, seria substituído por alguém muito pior — provavelmente um linha-dura que nem manteria a aparência de respeitar os direitos humanos." ${ }^{33}$

Essa leitura era a mais conveniente para a embaixada e para o Departamento de Estado, porque garantia a "neutralização" de forças de esquerda na região, permitia que os negócios seguissem fluindo e garantia a influência dos EUA no país, evitando que pressóes em favor dos direitos humanos acabassem conduzindo-o às mãos da linha-dura, de perfil acentuadamente nacionalista. Nesse aspecto, seguiam o padrão dos casos anteriores, do Brasil e do Chile.

\footnotetext{
81 "The problem is that the United States is an idealistic and moral country and its citizens have great difficulty in comprehending the kind of problems faced by Argentina today. There is a tendency to apply our moral standards abroad (...)." Memorandum of conversation. US Argentine relations. 6/10/1976. NSA, AR00472.

82 "Terrorism and counterterrorism regularly left bodies in the streets well before the latest military coup." Cabo. Human Rights situation in Argentina. 27/8/1976. NSA, AR00395, p. 3.

83 "For most observers are convinced that if Videla is pushed aside, he would be replaced by someone far worse - probably a hardliner who would not even give lip service to respect for human rights." Idem. É importante notar que essa interpretaçáo era compartilhada por setores da sociedade argentina. NOVARO, Marcos. Cables secretos, op. cit., p. 42.
} 
Logo após a edição do AI-5 no Brasil, o general Vernon Walters escreveu uma carta a Henry Kissinger argumentando em favor da manutenção da proximidade das relaçôes dos EUA com o Brasil: "Se o Brasil se perder, não será outra Cuba, será outra China." ${ }^{84}$ Um tanto dramático, o argumento apoiava-se na grandeza territorial e na pretensão do país em tornar-se um ator regional e internacionalmente relevante. $\mathrm{O}$ caso do Chile era ainda mais grave aos olhos dos EUA porque o experimento de Allende, de construir um socialismo por vias pacíficas, atraía os olhos atentos da esquerda internacional, como ocorrera décadas antes com a república espanhola em sua luta contra o fascismo. Náo por acaso, em um memorando de preparaçấo da viagem de Henry Kissinger ao Chile, em 1976, William D. Rogers comparou o Chile à Espanha de Franco nos anos 1940, como "símbolo da tirania de direita" ${ }^{85}$ A situação da Argentina era diferente. Embora pudesse ser descrita pelo Departamento de Estado como uma potência regional, não tinha o mesmo histórico de afinidade com os EUA, nem se travava em seu interior uma luta ideológica com potencial para tornar-se um modelo internacional.

O envolvimento dos EUA com os golpes militares de cada uma dessas naçóes refletiu as avaliaçóes realizadas em cada caso e, como se viu, variou significativamente de país para país, embora nos três casos o apoio tenha sido inequívoco. Se houve discordâncias entre agências governamentais ou no interior de cada uma delas, até a eleiçấo de Jimmy Carter não foram consistentes o suficiente para alterar significativamente os rumos da política externa, mesmo com a atuação decidida de setores do Congresso contrários aos regimes autoritários. A aparente contradição entre um país orgulhoso de seus sólidos fundamentos democráticos e sua política externa de promoção e aliança com ditaduras militares de direita "resolveu-se" em duas operaçóes. A primeira construiu um argumento apoiado na noçáo de que os países da região não estavam maduros para viver uma democracia. A segunda, em um contexto político altamente polarizado, consistiu em empurrar para a direita o leque de opçôes, transformando os militares autoritários pró-EUA em "moderados", tática viabilizada pela ameaça de um risco maior, representado pelo setor nacionalista de ultradireita.

Com a eleição de Jimmy Carter, cuja campanha centrou-se na moralizaçấo do Executivo e na introdução dos direitos humanos na política externa, as ditaduras militares sentir-se-iam abandonadas pelo país que havia sido seu fiador na esfera internacional. Na América Latina, a Argentina seria adotada como um caso especial para testar a nova política: a guerrilha fora derrotada, o país não tinha valor estratégico para os EUA, não fora alvo de apoio efusivo como o Brasil, nem de operaçôes encobertas posteriormente conhecidas do público como o Chile, e possuía um enorme passivo de abusos aos direitos humanos. Mesmo assim, a política externa estadunidense esbarraria ao mesmo tempo nas ambiguidades da nova diretiva — em momentos em que questóes de

\footnotetext{
${ }^{84}$ KISSINGER, Henry apud GASPARI, Elio. A ditadura escancarada, op. cit., p. 339.

${ }^{85}$ Memorando. Overall Objectives for Your Visit to Santiago, 26/5/1976, NSA, CL01418. Citado por KORNBLUH, Peter. The Pinochet file, op. cit., p. 240.
} 
segurança ou mesmo de ordem econômica disputaram espaço com os direitos humanos — e nas limitaçôes que tinha ao lidar com governos não alinhados à sua proposta, que contradizia tudo o que havia sido feito até então. Além disso, pouco tempo depois os EUA voltariam aos trilhos da Guerra Fria, com Ronald Reagan, dessa vez dirigindo seu anticomunismo à América Central, já que no Cone Sul o perigo esquerdista fora subjugado. A retórica dos direitos humanos permaneceria na esfera internacional, porém dentro de uma chave conservadora. ${ }^{86}$

É sintomático o fato de que, ainda em 1976, o subsecretário de Estado para a América Latina, Harry Shlaudeman, sugerisse que, vencida a guerra contra a esquerda armada, era preciso "despolitizar os direitos humanos". ${ }^{87}$ Pode-se inferir que o subsecretário compreendeu que os direitos humanos estavam longe de representar uma ameaça fatal ao american way of life. Ao contrário, podiam servir de ferramenta política, seja para fazer uma crítica conservadora dos países do bloco socialista ou para chamar a atenção para o que estava acontecendo alhures. ${ }^{88}$ Integravam-se bem à retórica estadunidense de superioridade moral, liderança e excepcionalismo. Sua lógica de atuação era distinta: seus ativistas eram profissionalizados, focavam-se em indivíduos em vez de classes sociais, manejavam de forma crescente a publicidade, apelando à emoção mais do que ao engajamento político, faziam lobby junto ao Congresso em vez de convocarem a população para demonstrações de rua, arrecadavam doaçôes financeiras de grandes fundaçóes ou de setores sociais bem definidos em lugar de vender jornais ou recolher contribuiçóes de militantes. ${ }^{89}$ Polissêmicos, mas sobretudo voltados para proteger direitos políticos e de integridade pessoal, não eram disruptivos para a sociedade capitalista como o eram os projetos revolucionários de esquerda. Podiam, portanto, ser evocados quando a segurança ou os negócios não estavam em jogo.

\section{Fontes}

National Security Archive (NSA). Argentina (AR). Argentina, 1975-1980: The making of U.S. human rights policy information.

National Security Archive (NSA). Chile (CL). Chile and the United States: U.S. policy toward democracy, dictatorship and human rights, 1970-1990.

National Security Archive (NSA). Electronic Briefing Books (EBB). Disponível em: <http:// nsarchive.gwu.edu/NSAEBB/>. Acesso em: fev. 2017.

\footnotetext{
${ }^{86}$ KEYS, Barbara J. Reclaiming American Virtue. The Human Rights Revolution of the 1970's, op. cit., p. 362.

${ }^{87}$ ARA monthly report. The third world war and South America. 3/8/1976. NSA, AR00356. CL01472, p. 5.

${ }^{88}$ KEYS, Barbara J. Reclaiming American Virtue. The Human Rights Revolution of the 1970's, op. cit., p. 7.

${ }^{89}$ Para uma discussão crítica sobre os sentidos e os efeitos do movimento dos direitos humanos, ver KELLY, Patrick William. "Magic Words”. The Advent of Transnational Human Rights Activism in Latin America's Southern Cone in the Long 1970s, op. cit.; CMIEL, Kenneth. The Emergence of Human Rights Politics in the United States, op. cit.; CMIEL, Kenneth. The Recent History of Human Rights. American Historical Review, p. 117-135, fev. 2004.
} 
National Security Archive (NSA). CIA. Communist Potentialities in Latin America, 80/90-64, 19 August 1964 - Revolution and subversion in Latin America. Selected U.S. intelligence community estimative products, 1947-1987.

National Archives and Records Administration (NARA), Record Group (RG) 59: General Records of the Department of State.

Arquivo Nacional (AN), Fundo Comissão Nacional da Verdade (CNV).

Time Magazine, v. 63, n. 2, 11 jan. 1954.

\section{Referências bibliográficas}

CMIEL, Kenneth. The Emergence of Human Rights Politics in the United States. Journal of American History, v. 86, n. 3, p. 1231-1250, 1999.

fev. 2004.

. The Recent History of Human Rights. American Historical Review, p. 117-135,

DINGUES, John. Os anos do Condor. Uma década de terrorismo internacional no Cone Sul. São Paulo: Companhia das Letras, 2004.

ECKEL, Jan; MOYN, Samuel (Eds.). The Breakthrough. Human Rights in the 1970's. Pensilvânia: University of Pennsylvania Press, 2014.

FICO, Carlos. O grande irmão: da operação Brother Sam aos anos de chumbo. Rio de Janeiro: Civilização Brasileira, 2008a.

- Os golpes de 1964 e 1966 no Brasil e na Argentina e o papel dos EUA. In: Anais do Seminário Internacional Ditadura e Democracia na América Latina: Balanço Histórico e Perspectivas. Rio de Janeiro: Fundação Getulio Vargas, 2008b. p. 53-76. v. 1.

FRANCO, Marina; IGLESIAS, Mariana. El estado de excepción en Uruguay y Argentina. Reflexiones teóricas, históricas e historiográficas. Revista de História Comparada, Rio de Janeiro, v. 5, n. 1, p. 91-115, 2011.

GASPARI, Elio. A ditadura envergonhada. São Paulo: Companhia das Letras 2002a.

- A ditadura escancarada. São Paulo: Companhia das Letras, 2002 b.

- A ditadura encurralada. São Paulo: Companhia das Letras, 2004.

GREEN, James. Apesar de você. São Paulo: Companhia das Letras, 2009.

HARMER, Tanya. Allende's Chile and the Inter-American Cold War. Chapel Hill: University of North Carolina Press, 2011.

HUGGINS, Martha. Polícia e politica. São Paulo: Cortez, 1998.

KEYS, Barbara J. Reclaiming American Virtue. The Human Rights Revolution of the 1970's. Cambridge: Harvard University Press, 2014.

KEYS, Barbara J.; KECK, Margaret E. Activist Beyond Borders: Advocacy Networks in International Politics. Ithaca, NY: Cornell University Press, 1998. 
KELLY, Patrick William. "Magic Words". The Advent of Transnational Human Rights Activism in Latin America's Southern Cone in the Long 1970s. In: ECKEL, Jan; MOYN, Samuel (Eds.). The Breakthrough. Human Rights in the 1970's. Pensilvânia: University of Pennsylvania Press, 2014, p. 88-106.

KORNBLUH, Peter. The Pinochet File. Nova York: New Press, 2013. (e-book).

KUNZ, Diane B. (Ed.). The Diplomacy of the Crucial Decade. American Foreign Relations During the 1960. Nova York: Columbia University, 1994.

MORGAN, Michael Cotey. The Seventies and the Rebirth of Human Rights, In: FERGUSON, Niall; MAIER, Charles S.; MANELA, Erez; SARGENT, Daniel J. The Shock of the Global: the 1970s and the rebirth of human rights. Cambridge, MA: Belknap Press of Harvard University Press, 2010, p. 237-250.

MOTTA, Rodrigo Patto Sá. Modernizando a repressão. A Usaid e a polícia brasileira. Revista Brasileira de História, v. 30, n. 59, p. 237-266, jun. 2010.

NOVARO, Marcos. Cables secretos. Buenos Aires: Edhasa, 2011.

PADRÓS, Enrique Serra; SIMOES, Silvia. A ditadura brasileira e o golpe de Estado chileno. Outros Tempos, v. 10, p. 233-261, 2013.

QUADRAT, Samantha Viz. A emergência do tema dos direitos humanos na América Latina. In: FICO, Carlos; FERREIRA, Marieta de Moraes; ARAÚJO, Maria Paula; QUADRAT, Samantha Viz (Orgs.) Ditadura e democracia na América Latina. Balanço histórico e perspectivas. Rio de Janeiro: Fundação Getulio Vargas, 2008, p. 361-395.

RAPOPORT, Mario; LAUFER, Rubén. Os EUA diante do Brasil e da Argentina: os golpes militares da década de 1960. Revista Brasileira de Politica Internacional, v. 43, n. 1, p. 69-98, 2000.

SCHMIDLI, William Michael. The Fate of Freedom Elsewhere. Human Rights and U.S. Cold War Policy Toward Argentina. Ithaca: Cornell University Press, 2013.

SCHMITZ, David F. The United States and Right-wing Dictatorships. 1965-1989. Cambridge: Cambridge University Press, 2006.

SIKKINK, Kathryn. Mixed Signals. U.S. Human Rights Policy and Latin America. Ithaca, NY: Cornell University Press, 2004.

SPEKTOR, Mathias. Kissinger e o Brasil. Rio de Janeiro: Zahar, 2009.

WALKER, William O. Mixing the Sweet with the Sour: Kennedy, Johnson, and Latin America. In: KUNZ, Diane B. (Ed.). The diplomacy of the Crucial Decade. Nova York: Columbia University, 1994, p. 42-79.

\section{Como citar:}

JOFFILY, Mariana. A política externa dos EUA, os golpes no Brasil, no Chile e na Argentina e os direitos humanos. Topoi. Revista de História, Rio de Janeiro, v. 19, n. 38, p. 58-80, mai./ago. 2018. Disponível em: <www.revistatopoi.org>. 